\title{
CONDITIONS FOR LEGAL PROTECTION OF INVENTIONS IN THE FIELD OF NANOTECHNOLOGY
}

\author{
Bakhtiyor Usubjonovich Akhmadjonov \\ Lawyer of Ferghana State University, Candidate of Juridical Sciences (PhD), Ferghana region, \\ Republic of Uzbekistan
}

Article DOI: https://doi.org/10.36713/epra5142

\begin{abstract}
The article provides a detailed analysis of the conditions of legal protection of inventions in the field of nanotechnology and the formation of legal norms with the help of materials from the scientific literature.
\end{abstract}

KEY WORDS: Nanotechnology, legal norm, protection, invention, science, law, intellectual property.

\section{INTRODUCTION}

The current legislation of Uzbekistan does not contain norms aimed at regulating nanotechnology and related relations. Due to the fact that nanotechnology is the object of intellectual property, in the legislation aimed at the legal regulation of intellectual property ("On Inventions, Utility Models and Industrial Designs", "On Selection Achievements", "On Legal Protection of Integrated Circuit Topologies" and other laws) such as nanotechnology. In addition, the fact that nanotechnology is a branch of science and the issues related to their creation and application are still in the process of formation, and the lack of a clear decision on them also obscures the need for the formation of legislation and legislation. in the formation of negilism. Of course, this process is not dogmatic, and the perceptions and views on this issue will become clear after some time, and the need to create a legal framework for nanotechnology will become clearer, and the urgency of the issue will become clear. However, this does not mean that legal science can be excluded from social realities, or that the gap in the legal field will always remain so. On the contrary, the field of jurisprudence must go ahead and, in some cases, in line with modern realities, and determine the basis and procedure of legal regulation. Such a practice serves to prevent future legal conflicts, as well as the development of legal norms in line with modern realities.

\section{METHODS}

The uniqueness of nanotechnology as an object of intellectual property is characterized by the fact that the object and direction of creative activity is focused on extremely small objects, and as a result achieves achievements that can not be achieved under normal conditions. Therefore, it is necessary to pay attention to the definition of the essence of nanotechnology as an object of intellectual property, the recognition of the term "nanotechnology" as an object and its recognition as a separate independent object of intellectual property.

\section{RESULTS AND DISCUSSIONS}

As noted above, in a number of countries, nanotechnologies are recognized and protected as a form of invention rather than as a separate object of intellectual property. In addition, today a special and separate piece of legislation on the legal status of nanotechnologies has not yet been adopted in any country and is not widely used in law enforcement practice. However, more than half a century has passed since the term nanotechnology was recognized as a separate branch of science, and specific scientific laws have been created in this area. This shows the need and urgency of legal regulation of nanotechnology as a separate area of human scientific and creative activity, and one of the tasks of the legislature to determine the legal order of human scientific and creative activity is the field of nanotechnology. Of course, it should be noted that in 
some countries, certain normative documents aimed at the establishment, formation and development of nanotechnology activities have been adopted. For example, in countries such as the Russian Federation, the United States, France, Japan, Germany, certain normative documents on nanotechnology activities, government decisions have been adopted. However, these normative documents are aimed at the organization and formation of nanotechnology activities, which are a type of scientific research activity, and do not provide for the status of nanotechnology as an object of intellectual property.

The status of nanotechnology as an object of intellectual property is becoming more and more common in modern jurisprudence, defined by the legal regime of inventions. In fact, nanotechnologies are close to inventions in terms of their method of creation and practical and technical characteristics. In addition, nanotechnology is close to inventions, as it contributes to the development of technical progress and has a level of novelty and ingenuity. In this regard, it is possible to reveal the criteria for the legal protection of nanotechnological inventions by analyzing the application of the conditions of legal protection of inventions to nanotechnology.

According to Article 6, Part 1 of the Law of the Republic of Uzbekistan "On Inventions, Utility Models and Industrial Designs" of August 29, 2002, if an object specified as an invention has a new, inventive step and can be used in industry, it is legally protected.

According to O. Akyulov, according to US law, an invention must have signs of novelty, usefulness and invisibility. The utility mark does not require an indication of the degree to which the invention is useful. In an explanation given as early as 1817, the U.S. Supreme Court ruled that an invention was sufficient if it could be applied in practice and if the application was not contrary to politics and ethics. In the laws of Uzbekistan and Russia, the sign of industrial application of the invention was not logically correct. In this case, the term used in industry can be considered as incomplete and inaccurate in its content. It was necessary to use the phrase in practice here [1, p.117$118]$.

If the invention is not known from the level of technical development, it is considered new. According to I.I. Nasriev, patents issued for industrial property under the Law "On Inventions, Utility Models, Industrial Designs" can be disputed during the term of its validity and can be partially or completely revoked. The main reason for such cases may be the novelty of industrial property. In determining the novelty of inventions and utility models, the technical level of applications submitted by applicants across the country plays an important role [2].
According to V.D. Yusupov, the concept of novelty is revealed through the level of technology. An invention is considered new if it does not relate to the level of technical development at the date of application, and the concept of "level of technical development" includes any knowledge that is available to the public through written or oral description or otherwise. Thus, there is an absolute global demand for the invention [3]. According to A.P. Sergeev, the novelty of an invention is determined by its priority date. The priority date is determined by the filing of a patent application with the Patent Office [4].

According to O.Akyulov, the priority date of the application for an object of industrial property begins from the date of registration of the application and its submission to the patent office. It is known that Uzbekistan is a party to the Paris Convention for the Protection of Industrial Property. Therefore, the priority date of the Convention is applied in the territory of the Republic of Uzbekistan [1, p.123124].

In our view, novelty cannot be attributed to a previously unknown state of affairs relative to an invention. The novelty of the invention is characterized not only by the fact that it has not been the same before, but also by the fact that a solution has been found with respect to substance and method. Only then can the invention be considered new. In nanotechnology, too, innovation is associated with previously unknown, and if it is not known from the level of development of nanotechnology, it can be noted that it is considered new. However, evaluating nanotechnologies only as a solution to an existing technical problem would be a relatively narrow interpretation of their potential. Nanotechnologies not only represent the solution of a technical problem but also the solution of a problem in any sphere of social life and human activity, take the existing substance, body and method to a new level and raise their potential to a new and higher level. For example, the use of nanoproducts in medicine may be safer, more beneficial than previously used substances and methods, and may prolong human life and enhance adverse effects on natural conditions.

In accordance with paragraphs 3-4 of Article 6 of the Law "On Inventions, Utility Models and Industrial Designs", an invention has the degree of invention if it is not clear from the data on the level of technical development. The state of the art includes any information disclosed to the public worldwide prior to the priority date of the invention. Inventive activity is identical to the criterion of "degree of invention", which was previously used in the judicial and administrative practice of a number of countries.

The previous practice of the EU administrative and judicial authorities has developed a number of auxiliary criteria for assessing inventive 
activity, which can be considered to have been applied in many countries of the European Patent Convention.

In particular, the following solutions are recognized as inventive activities:

- a solution to a problem that experts have not been able to find for a long time, despite repeated attempts, despite the need;

- the existing invention is not in a position to meet current needs;

- the existence of significant technical difficulties that need to be overcome in the creation of the invention.

Proof of the inventive activity is the elimination of "technical assumptions", conservatism and "technical blindness" of specialists, which did not allow to find a certain optimal solution, which is clearly visible at the level of technical development.

Based on the criterion of abstraction, it should be noted that in foreign legislation the criterion of technical progress, which was previously considered an invention of enrichment of technical means (GFR, Austria, Switzerland) was abolished. Consequently, the creation of a technical tool or the solution of a task in technical methods satisfies a certain need, which can be considered as enriching the overall level of technical development [5, p.66-67].

According to the general rule, inventions are new equipment, means of production, new working devices that help to solve an existing technical problem in the field of technology and are useful for production. Given the place of inventions in public life and the state economy, their usefulness is considered as the first tool. Given that the invention is usually carried out in the field of technology, most experts consider them as the result of scientific and creative activity aimed at solving a technical problem and the solution of an existing problem [6, p.342346].

According to S.M. Safoeva, the main purpose of the invention is to find a solution to the problem in the field of technology and its usefulness for industry. An invention is a patent-protected object of intellectual property, which, according to the object of scientific and creative activity, has a special place in the system of intellectual property and differs from other objects of intellectual property by the following features:

- Firstly, of intellectual property, only the invention is the product of research in engineering and industry;

- Secondly, the process of creating inventions is characterized by its complexity and longevity;

- Thirdly, inventions are not included in the list of objects of intellectual property protected after their objective form, but are protected by a special protection document issued by the relevant state body [7]. While the level of invention is associated with a state of "uncertainty", it should be borne in mind that the term "level of technical development" is derived from the latest innovations and achievements of modern science. Of course, in the context of globalization and integration, the state of "uncertainty" cannot be linked to the territory or shell of a single country. However, in determining the fact of "obvious ambiguity" it is necessary to take into account that such a solution to the existing problem in relation to the substance or method has not yet been formed at all. Uncertainty at the level of technical development is also related to the date and status of the priority, in which the first application for the protection of the invention serves as the basis for its protection. In nanotechnology, too, the state of uncertainty at the level of technical development is important. It would be more accurate to say that this situation is not clear to them at the level of development of nanotechnology. Such ambiguity is related to the term of the application for legal protection of nanoproducts. In addition, there may be problems in defining the state of "uncertainty" in terms of the confidentiality of advances in nanotechnology.

Another condition for the patentability of inventions is that they can be used in industry. The possibility of application in industry means that the new device, substance or method created represents not only the theoretical existence, but also the solution of an existing technical problem from a practical point of view. In fact, while the invention is considered to be a useful, new and problematic solution in terms of all technical and economic parameters, it must be a complete and widely applied fact in the relevant field. Otherwise, the existence of such an invention and a new only scientific hypothesis will remain a hypothesis, and there will be no specific necessity to protect it from a legal point of view and to define its status as an object of law. The legal literature also contains a number of opinions on the state of industrial applicability of the invention. For example, V.D. Yusupov noted that the criterion of industrial applicability served as a basis for the exclusion of a number of objects from the list of patentable objects, and in this regard, the legislation provides for surgical or therapeutic methods of treatment of humans and animals, as well as diagnostic methods. it has been determined that it does not meet the requirement of industrial applicability [8]. According to I.V. Biryukova, the development of the range of objects recognized as patentable shows that the scope of the subject of patenting is expanding. This is based on the introduction of various new industries in connection with the establishment of protection against objects previously considered incompetent [9]. 


\section{EPRA International Journal of Research and Development (IJRD)}

\section{CONCLUSION}

Indeed, while the legislation of each country gives legal protection to an invention, it also takes into account, first and foremost, the question of how the invention will benefit from an economic point of view and the need to pay special attention to its industrial application. The impossibility of industrial application is a ground for refusing to grant a patent for an invention. In the case of nanotechnology, it is possible to examine the feasibility of industrial application and how this technology will benefit and facilitate the relevant industry, and, consequently, to establish legal protection for nanotechnology. In general, any nanotechnological development can be the result of scientific research in terms of novelty, and this fact can be recognized in the field of science. However, if there is no possibility of industrial application of nanotechnological development, it is not subject to legal protection, and the issue of protection as a separate object of intellectual property may be possible only from the point of view of copyright. For example, if a person who violates the theoretical principles of nanotechnology publishes a work in the form of a material carrier, the work is copyrighted and is not protected by a patent as a nanotechnology, as this development can not be used in industry.

\section{REFERENCES}

1. Akyulov $O$. Theoretical and practical problems of the legal status of intellectual property. -Tashkent, 2004. -p. 117-118.

2. Nasriev I.I. Civil law issues of implementation and protection of personal non-property rights. Tashkent: Gafur Gulom Publishing House, 2006. $175 p$.

3. Yusupov V.D. International legal regulation of the protection of intellectual property: Abstract dissertation for the degree Candidate of Juridical Sciences. - Tashkent: 2012.-65 p.

4. Sergeev A.P. Civil law. -Moscow: Prospect, 2001. $418 p$.

5. Yusupov V.D. International legal regulation of the protection of intellectual property: Abstract dissertation for the degree Candidate of Juridical Sciences.-Tashkent, 2012.-p. 66-67.

6. Imomov N. Selection achievements are a specific object of intellectual property // "Civil law of the Republic of Uzbekistan for ten years of its independence". Abstracts of the international scientific and practical conference. -T.2002. p. 342346

7. Safoeva S.M. Forms of commercial use of intellectual property. Study guide. - Tashkent: TSJI, 2009. - 32 p.

8. Yusupov V.D. International legal regulation of the protection of intellectual property: Abstract dissertation for the degree Candidate of Juridical Sciences. - Tashkent, 2012.- 68 p.

9. Biryukova I.V. Problems of bio patent regulation and its improvement: Abstract dissertation for the degree Candidate of Juridical Sciences. -Tashkent, 2006. 